\title{
Discussion on the Development Strategy of China's Multimodal Transport Stations
}

\author{
Sixiang Huang ${ }^{1, a}$, Dong $\mathrm{Mu}^{2, \mathrm{~b}}$ \\ ${ }^{1}$ School of Beijing Jiaotong University, Beijing 100044, China; \\ 2 School of Beijing Jiaotong University, Beijing 100044, China. \\ ahqq9507@163.com, bdmu@bjtu.edu.cn
}

\begin{abstract}
The development of China's logistics industry has got tremendous opportunities from the "One Belt and Road" strategy. The interconnection between China and the countries along the route has not only enhanced trade relations, increased economic efficiency, but also brought opportunities for the development of China's multimodal transport. Based on the experience of developing multimodal transport in Europe and the United States and the current situation of China's multimodal transport, this paper summarizes and extracts many problems of China's multimodal transport station and proposes the development strategy of China's multimodal transport station.
\end{abstract}

Keywords: The "One Belt and Road" strategy; Multimodal Transport; Distribution Stations.

\section{Introduction}

In recent years, the development of China's economy has put forward higher requirements for the transportation industry. A single mode of transportation is increasingly unable to meet customers' low-cost, high-efficiency transportation requirements. Multimodal transport is an organic combination of two or more modes of transport. It captures and integrates the advantages of various modes of transportation and is an advanced mode of transportation. The "One Belt and Road" strategy has provided an opportunity for the development of China's multimodal transport and put forward higher requirements for multimodal transport. The development of multimodal transport has been designated as a national level strategy and has become one of the important tasks of the transportation industry $[1,2]$.

The area along the "One Belt and Road" has a population of about 4.4 billion people and a total economic output of about 21 trillion US dollars, accounting for $63 \%$ and $29 \%$ of the whole of world. With the implementation of the "One Belt and Road" strategy, transportation such as roads, railways, ports, and aviation will achieve tremendous growth [3]. With the rapid development of China's multimodal transport, there are higher requirements for logistics stations. Advanced logistics stations can not only fully utilize the multimodal transport efficiency of different modes of transportation, reduce transportation costs, but also help achieve the goal of standardized and integrated transportation of multimodal transport. Therefore, in the period of vigorous development of container multimodal transport in the country, the improvement and optimization of logistics stations are becoming more and more important [4].

\section{Multimodal Transport Development}

Multimodal transport is recognized as the most efficient transportation service method in the world, which is conducive to improving logistics efficiency and reducing logistics costs. As a pioneer in the development of multimodal transport, Europe and the United States have accumulated very mature experience in the development of multimodal transport, but the original intention of development is similar to the current situation in China. By analyzing the experience of multimodal transport development in Europe and the United States, we can provide consideration for the development of multimodal transport in China. 


\subsection{World Multimodal Transport Development and Trends}

Multimodal transport originated around 1960. The earliest rise was the organic combination of railway transportation and road transportation, commonly known as "humpback transportation." With the rapid development of container technology, multimodal transport has gradually developed. In the 21 st century, developed countries such as Europe and the United States will operate as a leading strategy for logistics and transportation. Through various policy measures, a multimodal transport service system with diverse multimodal transport, advanced facilities and equipment, and complete standard systems has been formed. The system has good prospects for development.

(1) Multimodal transport is the strategic direction of the development of the global logistics industry [5]. The experience of European and American countries shows that multimodal transport can improve transportation efficiency by about $30 \%$, reduce cargo damage by about $10 \%$, reduce transportation costs by about $20 \%$, and reduce greenhouse gas emissions by about $70 \%$. Particularly, multimodal transport based on rail and sea-rail multimodal transport is strongly supported by European and American countries because it can optimize the transport structure, solve the economic problems in integrated transportation, reduce the total cost of logistics, and develop the animal industry to green.

(2) The volume of multimodal transport has grown rapidly. In recent years, the development of multimodal transport in developed countries such as Europe and the United States has maintained a rapid growth trend. From 1997 to 2011, the volume of multimodal transport in the United States increased from 217 million tons to 1.62 billion tons (an increase of 6.5 times), accounting for 9.2\% of the total freight volume. It is estimated that by 2040, the volume of US multimodal transport will reach 3.575 billion tons, accounting for $12.5 \%$ of the total freight, the value of freight will reach 10 trillion US dollars, accounting for $25.3 \%$ of the total value of freight.

(3) Road-rail transportation has become the main mode of multimodal transport. US road-rail transportation volume accounts for $53 \%$ of all multimodal transport, with a corresponding turnover of $57 \%$. The railway company bears the leading force. More than 800 kilometers are generally undertaken by the railway. Among them, 7 I-level railway companies account for more than $33 \%$ of the total freight volume, and the largest company BNSF accounts for about $50 \%$ of the total multimodal transport volume [6].

\subsection{Status and Problems of China's Multimodal Transport Development}

China's vast territory has certain similarities with the United States. Therefore, the experience of the United States in developing multimodal transport is more useful for China. Since 2016, the Chinese government has intensively issued articles to encourage the development of multimodal transport. According to official government forecasts, in 2020, multimodal transport is expected to increase by a factor of 1.5 compared to 2015 . By then, the proportion of multimodal transport will reach $7.25 \%$, an increase of 4.35 percentage points over 2015. Based on this calculation, by 2020 , the total cost of social logistics will drop by 3.9 percentage points, and the cost savings will be about 435 billion yuan.

After years of construction and development, China's transportation infrastructure has been continuously improved. China has built a multi-level integrated transportation network with railways, highways, waterways, aviation and pipelines. By the end of 2017, the national expressway mileage reached $131,000 \mathrm{~km}$, the railway operating mileage reached $127,000 \mathrm{~km}$, the coastal port had more than 2,300 berths of 10,000-ton or above, the number of civil aviation transportation airports reached 218 , and the number of various logistics stations reached 1,210. Container production and sales accounted for more than $90 \%$ of the global market share. China has basically achieved the connection of public, iron and water container transportation, and has the basic conditions for developing multimodal transport in a deeper and wider scope. However, there are still many problems in multimodal transport, mainly including:

(1) Container multimodal transport logistics station is not mature. China's current container multimodal transport is port-led, and inland stations far from the port are limited in development due to lack of policy support and government investment. The office configuration of many inland station 
ports is not perfect, and there is no function such as customs clearance and inspection. After the goods are transported by rail to the port, they need to be re-inspected and reported, which greatly affects the efficiency of container multimodal transport.

(2) Lack of multimodal transport facilities. Multimodal transport cannot be smoothly connected. Taking the railway as an example, only $1.3 \%$ of the container throughput of China's seaports is transferred to the port by rail, $85 \%$ by road, and the remaining $14 \%$ by water [7]. In the world's largest Shanghai Port, only $0.5 \%$ of containers are transported by rail, the advantage of railway cannot be achieved.

(3) Container multimodal transport cannot form large-scale transportation. China's supply of goods varies greatly, resulting in a very unbalanced supply of goods (for example, the northwest region is dominated by coal and petrochemical production, and the North China region is dominated by manufacturing output, etc.). Container multimodal transport often presents the status quo of one-way goods, and it is difficult to achieve economies of scale. In addition, the government lacks subsidies for enterprises that provide empty containers, which is not conducive to the popularization and development of container multimodal transport.

(4) Container multimodal transport lacks information collection and processing. The development of container multimodal transport integration is an important measure to improve the efficiency and service quality of container multimodal transport. At present, many enterprises are committed to the construction of the railway-waterway intermodal information platform. However, the actual operation is not perfect. The various nodes in the intermodal link have their own policies and have not reached the necessary consensus on information sharing.

\section{Problems in China's Logistics Stations}

The development of domestic and international multimodal transport must rely on the intelligent logistics platform of online and offline fast transactions to achieve effective linkage between "Sky Network" and "Ground Network". As the main component of the "Ground Network", the logistics station is the carrying entity that realizes the "Internet + Logistics". At present, the development problems of logistics stations in China are mainly reflected in:

\subsection{Incomplete Infrastructure}

Traditional logistics stations have problems such as small container loading and unloading sites, insufficient storage capacity, and mismatching of short-distance transportation vehicles. Some of the logistics stations have backward loading and unloading equipment, and low loading and unloading efficiency, resulting in the replacement of containers for multimodal transport. The cost is too high.

\subsection{Single Basic Logistics Business}

The main business of the current logistics station is warehousing, loading and unloading, and house leasing. Packaging, distribution, distribution processing, information analysis and other high-value, high-profit service content has not become a major profit item. Most of the multimodal transport projects rely on existing offline contact methods, the radiation range is limited, and business expansion is blocked.

\subsection{Insufficient Integration of Logistics Station}

At present, the management platform and information platform of the station are still under construction. The platform customer group and coverage are relatively simple, and the functional modules are few. The integration capability of the multimodal transportation scheme is insufficient, and the customer comparison space is narrow. The integrated platform of multimodal transport also needs constant exploration and improvement.

Therefore, China urgently needs to comply with existing policies to strengthen the construction of site infrastructure. According to market needs and potential customer needs, logistics companies carry out logistics service projects such as packaging, distribution and distribution processing at the station. 
The station and the company cooperated with each other to achieve win-win results, promote mutual development, and create a new mode of new logistics station.

\section{Development Strategy of China Multimodal Stations}

\subsection{Strengthen Stations Infrastructure}

At present, there are more than 1800 logistic stations in China's railways, such as small scale, backward loading and unloading equipment, and insufficient special machinery. Logistics stations should further increase investment in technical equipment, accelerate the development of equipment renewal, improve the adaptability of railway container transportation to the market [8]. Large-scale regional stations introduce customs and inspection and quarantine functions in accordance with the requirements of inland ports.

In the process of transform the logistics station, it is necessary to arrange and allocate the size of the logistics stations within the established land area, which can meet the requirements of loading, unloading, handling and storage of containers.

The total number of containers required in the logistics station area is determined according to factors such as the number of working containers per day of arrival, transmission, and transfer containers, and the occupied container time and the number of stacking layers. The number of daily averages of various types of containers in the logistics stations shall be determined according to factors such as the annual arrival container of the railway comprehensive logistics station, the number of transport containers, the number of transfer containers and the fluctuation coefficient of the container volume, etc., which can be calculated according to the following formula:

$$
N_{i}=\frac{Q_{i}^{*} \alpha}{365}
$$

Indices:

$N_{i}$ : daily average of various types of containers in the logistics stations.

$Q_{i}$ : number of various types of containers in the logistics stations per year.

$\alpha$ : volatility coefficient.

$i$ : container type.

The daily average of working containers in the logistics station shall be determined according to the number of working containers such as the daily average arrival container, the delivery container, the transfer container and the empty container generated or required according to the calculation of the balance, which can be calculated according to the following formula:

$$
N=N_{a}+N_{d}+N_{t}+\left|N_{a}-N_{d}\right|
$$

Indices:

$N$ : daily average of containers in the logistics stations.

$N_{a}$ : daily average of arrival containers.

$N_{d}$ : daily average of delivery containers.

$N_{t}$ : daily average of transfer containers.

The total number of containers in the logistics station should be determined according to factors such as daily average of various types of containers in the logistics stations, the time while the containers in the logistics station, and the highest stacking level. It can be calculated according to the following formula: 


$$
M=\sum \frac{N_{i}^{*} t_{i}}{h_{i}^{*} \beta_{i}}
$$

Indices:

$M$ : total number of containers required for the logistics station.

$t_{i}$ : the time while the containers in the logistics station.

$h_{i}$ : the highest stacking level of each type of container in the logistics station.

$\beta_{i}$ : the layer height utilization factor of various types of containers in the logistics station.

The number of loading and unloading operation areas in the logistics station area shall be determined according to factors such as the number of containers required in the logistics station area, the loading and unloading process, and the layout of the logistics station. It can be calculated according to the following formula:

$$
Z=\frac{M}{n^{*} m}
$$

Indices:

$Z$ : the number of loading and unloading areas in the logistics station.

$n:$ the number of rows in each loading and unloading operation area.

$m$ : the number of bits per row in each loading and unloading area.

The number of containers required in the logistics station area shall be determined according to daily average of various types of containers in the logistics stations and the time while the containers in the logistics station. It can be calculated according to the following formula:

$$
E=\sum N_{i} * t_{i}
$$

Indices:

$E$ : number of containers required to be held by the logistics station.

\subsection{Improve the Station Function}

Modern logistics stations should have the functions of container transportation and loading and unloading, multimodal transport and mouth-to-mouth service, inspection and maintenance of loading and unloading and transportation machinery, and railway transportation information. According to the needs of transportation, the logistics station also has the functions of international intermodal transportation of containers, disinfection and storage of containers, empty container allocation and cargo storage ${ }^{[9]}$. In order to improve the operational efficiency of container multimodal transport on the port side, the inland logistics station should also have complete functions such as customs declaration and inspection, and truly meet the process of container multimodal transport one-stop service.

\subsection{Strengthen the Construction of the Station Information Platform}

First, promote the related work of the construction of the information public service platform, and promote the railway, customs, commodity inspection, port and logistics enterprises involved in the operation to jointly construct and use the information public platform, open information interfaces, share information resources, break information barriers, and improve operational efficiency. The second is to promote advanced information technology and equipment, promote the widespread application of radio frequency identification (RFID), bar code equipment and other technologies. The third is to formulate relevant standards for multimodal transport information sharing and data transmission, promoting the interoperability of multimodal transport related information by standards. 


\subsection{Implement Integrated Operations}

Give full play to China's mixed ownership economic advantages. Encourage logistics stations to conduct strategic alliances with large transportation companies, manufacturers and third-party logistics companies to establish multi-modal transportation operations. Encourage logistics stations to conduct strategic alliances with large transportation companies, manufacturers and third-party logistics companies, and establish multi-modal transportation operations. The logistics station can design the intermodal service products of each logistics operation entity and establish a benefit sharing mechanism ${ }^{[10]}$. Logistics station also needs to rely on the logistics information tracking feedback of the Internet platform to improve the level of logistics services.

\section{Summary}

As a global economic power, China will surely achieve economic recovery and realize the Chinese dream under the "One Belt and Road" strategy. The development of multimodal transport logistics stations is an upgrade of the logistics industry and a development challenge. Relying on the development of the national economy and science and technology development of logistics parks, we must conform to the development trend of the world's multimodal transport and build a global circulation channel. The government needs to help large companies go abroad, integrate into the global trading partner array, and fully build China's important role in the integrated transportation system. Under the guidance of national policies, strengthening the construction of logistics stations can realize the "seamless convergence of hardware" and "unification of rules on software" in China's logistics industry, which will help achieve the goal of national supply-side reform.

\section{Acknowledgements}

Research on Logistics Resources Low-Integrating mode and Dynamic Decision. China natural science foundation project 2015,1-2018,12. No. 71473013.

\section{References}

[1]. Jianbang Du, Qing Li, Fengxiang Qiao, Lei Yu. ESTIMATION OF VEHICLE EMISSION ON MAINLINE FREEWAY UNDER ISOLATED AND INTEGRATED RAMP METERING STRATEGIES. Environmental Engineering \& Management Journal (EEMJ). May2018, Vol. 17 Issue 5, p1237-1248. 12p.

[2]. J Du, Q Li, F Qiao. Impact of Different Ramp Metering Strategies on Vehicle Emissions Along Freeway Segments Journal of Transport \& Health 9, S51 2018.

[3]. Q Li, J Du, F Qiao, L Yu. Characterizing Particulate Matter 2.5 Concentration Pattern within a Transportation Network: A Case Study in the Port of Houston Region. Journal of Pollution. 2018, 1 (106).

[4]. Hongmei Cheng. Discussion on the Development Strategy of Internet Plus Multimodal Transport Logistics Park [J]. Railway Economics Research, 2017(06):22-25.

[5]. Xiaoping Tan. "Internet Plus" multimodal transport provides the basic platform for modern logistics [N]. China Transportation Paper, 2016-08-17(008).

[6]. Hengying Zhuge, Xiangchun Qi, Langya Zhou. Inspiration of American Railway Intermodal Transport Development [J]. Railway Transport and Economy, 2016, (12):69-73.

[7]. Ming Wang. Do a good job in the multimodal transport of the Yangtze River port [N]. Economic Daily News,2016-12-30. 
[8]. Lei Yang. Intermodal Development Experience in the US and its Enlightenment [J]. Railway Freight Transport, 2018, 36(05):55-58.

[9]. Qiuchen Wang. Changchun railway comprehensive freight yard design [D]. Southwest Jiaotong University,2016.

[10]. Sixin Xie, Xiumin Sun. Research on the development mode and strategy of logistics multimodal transport under the "One Belt and Road" strategy [J]. Railway Purchase and Logistics, 2017, 12(01):51-54. 